\title{
Functional disorders, Cartesian dualism and stigma: where does the dualism really lie?
}

\author{
Anthony S David
}

This is a timely reappraisal of one of Oliver Sacks' less well-known works. The authors argue that the sense of detachment from his leg that Sacks felt after his injury and surgery was 'functional/psychogenic'. 12 Stone and colleagues take Sacks' account at face value and are at pains to label it repeatedly as 'genuine'. Their aim is to go beyond Cartesian dualism, a common aspiration but one hard to achieve in practice, such is the hold it has on our explanatory frameworks. Stone et al approach the 'case' like the good clinicians that they are and attempt to 'get above the lesion'. There is no mind-brain divide but there is a hierarchy: from the peripheral nerves up through the neuraxis to the cortex. But that is as far as it goes: in the materialist world, there is nothing else. A disorder of will seems the best formulation and is made without implied criticism or facetiousness.

The review is used didactically to provide us with an update on recent research in conversion disorder, also known as hysteria. The anecdotal association between injury and onset-as epitomised by Sacks' account-now has the status of 'fact' based on the authors' own case series and a meta-analysis. However, the mechanism underlying this association is still left unresolved. Sacks considered at one point a largely bottom up explanation-peripheral nerve injury interrupting normal proprioceptive and other feedback-but later dismissed this. His final explanation is of a disruption in body image or schema precipitated by the injury, not caused by a parietal stroke (also entertained at one point) but

Correspondence to Professor Anthony S David, Professor of Cognitive Neuropsychiatry, PO Box 68, Institute of Psychiatry, King's College London, London SE5 8AF, UK; anthony.david@kcl.ac.uk a functional (in the clean, physiological, non-hysterical sense) and as it turned out, temporary, reorganisation of cortical representations. The account of Stone et al is similar but tilts towards the motor-or premotor-system, equally functional in all senses but then what else is there?

Much popular neurology and lay understanding sets up an opposition between a complex understanding of the brain and psychiatry. Psychiatry is caricatured and limited to Freudian psychoanalysis. Unfortunately, in the eyes of believers or at least those for whom it suits to believe, the Freudian straw man can put up a decent fight. Spurious interpretations can be made of any event no matter how ridiculous it may be to do so. So, in Sacks' case, the initial 'trauma' of the fall while hiking is experienced as an humiliating and you might say emasculating event. So, if we were in fin de siècle Vienna, we might propose that 'the leg' was really nothing less than 'the penis'. Lifeless and immobile, the accident provokes a classic castration anxiety. In his helplessness at the bottom of the mountain, Sacks regresses to a time in childhood when he experienced the same state of mind, and when, much to his shock the young Oliver sees for the first time his father's genitals. Thrown into a heightened Oedipal conflict, his only solution is to 'disown' his own organ, to repudiate it for its lack of obedience to command. It's hogwash, of course: a comic interpretation. However, the damage is not that it is laughable or indeed potentially offensive to the individual but that it obscures what a true modern psychiatric formulation really looks like. The biopsychosocial approach excludes neither cortical schema nor discourse on motivation, and the possibilities of deception, self and other. Pertinent to conversion disorder is the notion of illness behaviour, and other social theories such as the sick role. Is it not one of the mechanisms whereby a minor injury can lead to major disability that it sows the seeds of what it might be like to be disabled and hence to be looked after, pitied, lionised? None of us is immune to this but like Sacks perhaps, most having glimpsed what life might be like on the 'other side' returns with haste to the land of the healthy.

VS Ramachandran, ${ }^{3}$ Sacks' literary godson discusses reorganisation of the cortical body schema following sometimes trivial peripheral injury as an explanation of some Complex Regional Pain Syndromes, a theory he suggests is supported by the response, often instantaneous, of some patients with this otherwise intractable syndrome to mirror visual feedback manipulations. This is where the happy 'we're-all-friends-together-let's-getrid-of-Cartesian-dualism' camaraderie breaks down. It is becoming clear that fixed dystonia and much of the Complex Regional Pain Syndromes is functional (in the dirty, non-physiological, psychiatric sense). Is talk of 'cortical representations' and the rest just the latest in a series of neuro-euphemisms? The aim to de-stigmatise functional disorders, as Stone and colleagues valiantly aim to do in their reinterpretation, is of course noble but I fear perhaps doomed. The dualism is not actually between brain and mind, which went in the nineteenth century, but between involuntary and voluntary. Try taking the stigma out of that-you might as well take the person out of medicine.

Acknowledgements The author thanks Alan Carson for his input.

Competing interests None.

Provenance and peer review Commissioned; externally peer reviewed.

Accepted 25 April 2012

J Neurol Neurosurg Psychiatry 2012;83:869. doi:10.1136/jnnp-2012-303051

\section{REFERENCES}

1. Stone J, Perthen J, Carson A. 'A Leg to Stand On' by Oliver Sacks: A unique autobiographical account of functional paralysis. J Neurol Neurosurg Psychiatry 2012;83:864-7.

2. Sacks OW. A leg to stand on. New York: Harper $\&$ Row, 1984

3. Ramachandran VS. The Tell-Tale Brain. New York: Norton and Co, 2011. 